\title{
Validity and Reliability Test of The Physical Exercise Movements Screening to Improve Fitness for Elderly
}

\author{
Cerika Rismayanthi ${ }^{1}$, Sugiyanto ${ }^{2}$, Agus Kristiyanto ${ }^{3}$, Muchsin Doewes ${ }^{4}$ \\ \{cerikafik@gmail.com ${ }^{1}$, sugiyantoprobo@gmail.com ${ }^{2}$, aguskriss@yahoo.co.id ${ }^{3}$ \} \\ Universitas Sebelas Maret Surakarta, Surakarta, Indonesia ${ }^{1,2,3}$
}

\begin{abstract}
Increased age experienced by each person will end with elderly age group, which is vulnerable to various activities due to physiological function decrease occurred. Instead of socio-psychological aspects, muscular function, cardiovascular, balance and mobility aspects are important factors that support our bodies work. The assessment in this study use the questionnaire of "Appropriate Movement for the Elderly" distributed to personal trainers for elderly. The results of the validity and reliability test can be concluded that questionnaire about screening exercises that are suitable for the elderly prove is consistent for all questions and valid for 40 movements, while 7 other movements (pressing the arm in front of the chest, Hyper-extension, Knee wrists to the left and right chest, Russian paw, Turn the arm in the direction of the needle clock, Cow Cat Attitude, and Raise sumo, raise calf on the wall) were invalid or not suitable for physical activities in elderly.
\end{abstract}

Keywords: physical activity, elderly, questionnaire, validity, reliability.

\section{Introduction}

The last development period in human life is in the old ages. Called development here does not mean development as experienced by adolescents. What is meant is psychological and social development. In this case the task of development in the elderly is the achievement of integrity in a person. This means that he managed to fulfill commitments in relations with himself and others, accepting the continuation of his age, accepting the limitations of his physical strength, maybe also accepting the illness he suffered. Instead he can also accept any other people's treatment of himself which is actually a reflection of his treatment to other people. If a person cannot achieve integrity, then he will experience discouragement. In addition, the task of developing the elderly is about moral commitment. The elderly should have a commitment to feel capable and have mastery of what they face [2]. Finally, the three commitments mentioned above are good in the struggle for life physically, economically, and psychologically. So it takes socio-psychological abilities in the lives of the elderly to support a variety of skills in old age. 
Broadly speaking, the elderly must have a passion in life. In a meta-analysis review of how the elderly respond to their lives, a relationship is found between sociopsychological abilities and the anxiety that surrounds the minds of many elderly people. To overcome anxiety, a statement was obtained that there is a potential relationship to exercise as a therapy for depression or anxiety, and the use of physical activity as a material to improve quality of life through strengthening self-esteem, improving mood, reducing anxiety, resistance to stress and improving sleep quality [6]. So it is required for the elderly to involve physical activity in aspects of improving their lives.

Elderly aged around 50 - 65 years old [15], experiencing various kinds of decreased physiological function, including muscle function, cardiovascular, etc. Muscle strength and power in performing isometric, concentric and eccentric movements decreased since the age of 40 years and a significant decrease occurred after the age of 65-70 years old [14]. Then the balance and mobility factors also decrease when they reach that age $[12,14,16]$. Based on these considerations, various kinds of movements are needed in accordance with the needs of the elderly. It is certainly cannot be equated with the usual movements carried out by people who are productive in the golden age.

Therefore, the objective of this study was to verify the construct validity and reliability of screening movements for elderly. The validation is needed from experts (in this case personal trainers or elderly instructors) to find out what movements are considered safe, easy and can prevent or slow down the aging process. On the other hand, it can help the elderly confident and be able to do various movements for daily activities.

\section{Method}

This research uses a mixed-method [4] in order to complement the data obtained, both from qualitative and quantitative data. Qualitative data were obtained through elderly interviews and quantitative data through descriptive research using a "Screening Movements for the Elderly" questionnaire as an instrument.

\subsection{The physical exercise movements screening questionnaire}

Several processes must be completed to get suitable movement for elderly. In the beginning, searching, finding, implementing theoretically and empirically from previous study to identify problems faced by older adults, which is include field study and need assessment. The next step was early product of training model for elderly, so that prototype research model created at the beginning of research flow. Comprehension and depth of learning literature united with research model prototype will through expert validation. If research model prototype considerably accepted, research model revised, after that, product completed.

The questionnaire was sent into personal trainer, in order to get any suggestion or opinion for improving details of questionnaire. This product (or questionnaire) confirmed by practitioners so that theory and practically blend accepted. Furthermore, screening movements for elderly questionnaire evaluated, implementing all suggestion from expertise, both theory and practical, afterwards got last revised then design finalization of questionnaire. After through all previous steps, validation and reliability of this questionnaire was measured. 


\subsection{Type of movement}

The questionnaire is used to have any exercise movements that are suitable for elderly, and have a small risk of injury or bodily imbalance that can cause falls in the elderly, as shown in Table I.

Table 1. Type of movement

\begin{tabular}{|c|c|c|}
\hline Exercise & No & Movement \\
\hline \multirow[t]{14}{*}{ Flexibility } & G1 & Spinal Stretches \\
\hline & $\mathrm{G} 2$ & Shoulder stretch \\
\hline & G3 & Lumbar stretches of left and right spine \\
\hline & G4 & Press your arms in front of your chest \\
\hline & G5 & Left and right triceps stretch \\
\hline & G6 & Biceps stretch standing left and right \\
\hline & G7 & Shoulder Gator \\
\hline & G8 & Rhomboid pull \\
\hline & G9 & Stretch the floor lying on your left and right sides \\
\hline & G10 & Scissors Arm \\
\hline & G11 & Child attitude \\
\hline & G12 & Hyperactivity \\
\hline & G13 & Snow Angel upside down \\
\hline & G14 & Knees to the left and right chest \\
\hline \multirow[t]{13}{*}{ Balance } & G15 & Russian punter \\
\hline & G16 & Raise your arms while standing \\
\hline & G17 & Raise your arms to the side \\
\hline & G18 & Rotate the arm clockwise \\
\hline & G19 & Rotate the arm counterclockwise \\
\hline & G20 & Triceps extension bent \\
\hline & $\mathrm{G} 21$ & Superman and swimmer \\
\hline & $\mathrm{G} 22$ & Lift the "Y" floor \\
\hline & G23 & Lift the calf facing the wall \\
\hline & $\mathrm{G} 24$ & Donkey kick to the left \\
\hline & $\mathrm{G} 25$ & Left and right quadrant exercises \\
\hline & G26 & Bowed body \\
\hline & $\mathrm{G} 27$ & Walk While carrying Ball Medicine \\
\hline \multirow[t]{17}{*}{ Strength } & $\mathrm{G} 28$ & Push up Hold low modification \\
\hline & G29 & Stomach Crunch \\
\hline & G30 & Mountain climber \\
\hline & G31 & Touch Heel \\
\hline & G32 & Abdomen tightening exercises \\
\hline & G33 & Punch \\
\hline & G34 & Raise your hands while standing \\
\hline & G35 & Raise your arms to the side \\
\hline & G36 & Cow Cat Attitude \\
\hline & G37 & Superman and swimmer \\
\hline & G38 & Supine Push Up \\
\hline & G39 & Squat \\
\hline & G40 & Side walk \\
\hline & G41 & Lunge backwards \\
\hline & G42 & Raise the sumo raise the calf on the wall \\
\hline & G43 & Bowed body \\
\hline & G44 & Lift the Stretcher Rest position \\
\hline
\end{tabular}




\begin{tabular}{lll}
\hline Group training & G45 & Sit down \\
& G46 & Stand up \\
& G47 & Stand while moving \\
\hline
\end{tabular}

Movement recommendations for the elderly. (Table footnote)

Questionnaire data analyzed using IBM Statistics 20 to do validity test (Pearson Correlation) and a reliability test (Cronbach's Alpha). After the calculation is complete, the results are obtained that can explain the data from the questionnaire that has been distributed to the personal trainers or instructors.

\section{$3 \quad$ Result and discussion}

\subsection{Validity test}

In this validity test obtained 47 forms of movement that are considered to be carried out by the elderly. However, to find out whether the form of movement is indeed safe and can be carried out by the elderly or not, it is necessary to test the validity of the experts (in this case personal trainers or instructors). Table 1. shows 47 movements that were deemed feasible.

From the data in Table 1, then the validity test is conducted to the experts to find out which movements can be carried out by the elderly. The following results are obtained; Provisions regarding determining whether it is valid or not can be seen from the $r$ table and the Sig. value (2-tailed), it is known that the amount of $\mathrm{N}=9$ (means that $\mathrm{N}=9$ because each movement is validated by 9 personal trainers), then obtained $\mathrm{R}$ table $=0.666$; with condition, if the value of Sig. (2-tailed) $<0.05$ with Pearson Correlation is positive, then the questionnaire items are declared valid.

It can be concluded that, 7 of 47 movements was invalid because of significant value more than 0.05 ( $\mathrm{p}$-value: $>0.05$ ), although $\mathrm{r}$ value has positive value. Invalid seven movements are: a). G4 (Press the arm in front of the chest) with p-value: 0,650 $>0.05$ and $\mathrm{r}$ value $=0.176<0.666 ; \mathrm{b}$ ). G12 (Hyperactivity) with p-value: $0,650>$ 0.05 and $\mathrm{r}$ value $=0.176<0.666 ; \mathrm{c}$ ). G14 (Ankle to left and right chest) with $\mathrm{p}$-value: $0,843>0.05$ and $r$ value $=-0.78<0.666 ; d$ ). G15 (Russian paver) with p-value: 0,843 $>0.05$ and $\mathrm{r}$ value $=-0.78<0.666$; e). G18 (Turn the arm clockwise) with $\mathrm{p}$-value: $0,650>0.05$ and $\mathrm{r}$ value $=0.176<0.666 ; \mathrm{f}$ ). G36 (Cow Cat Attitude) with $\mathrm{p}$-value: $0,971>0.05$ and $r$ value $=-0.14<0.666 ; \mathrm{g}$ ). G42 (Raise the sumo raise the calf on the wall) with p-value: $0,650>0.05$ and $r$ value $=0.176<0.666$.

As a result of calculating movement validity, we obtained suitable training movements for elderly, it can be seen in Table. II, as follows.

Table 2. Type of movement

\begin{tabular}{lll}
\hline Exercise & No & Movement \\
\hline Flexibility & G1 & Spinal Stretches \\
& G2 & Shoulder stretch \\
& G3 & Lumbar stretches of left and right spine \\
& G5 & Left and right triceps stretch \\
G6 & Biceps stretch standing left and right
\end{tabular}




\begin{tabular}{lll} 
& G7 & Shoulder Gator \\
G8 & Rhomboid pull \\
& G9 & Stretch the floor lying on your left and right sides \\
G10 & Scissors Arm \\
G11 & Child attitude \\
G13 & Snow Angel upside down \\
\hline Balance & G16 & Raise your arms while standing \\
& G17 & Raise your arms to the side \\
G19 & Rotate the arm counterclockwise \\
& G20 & Triceps extension bent \\
G21 & Superman and swimmer \\
G22 & Lift the "Y" floor \\
& G23 & Lift the calf facing the wall \\
G24 & Donkey kick to the left \\
G25 & Left and right quadrant exercises \\
G26 & Bowed body \\
G27 & Walk While carrying Ball Medicine \\
\hline G28 & Push up Hold low modification \\
G29 & Stomach Crunch \\
G30 & Mountain climber \\
G31 & Touch Heel \\
G32 & Abdomen tightening exercises \\
G33 & Punch \\
G34 & Raise your hands while standing \\
G35 & Raise your arms to the side \\
G37 & Superman and swimmer \\
G38 & Supine Push Up \\
G39 & Squat \\
G40 & Side walk \\
G41 & Lunge backwards \\
G43 & Bowed body \\
G44 & Lift the Stretcher Rest position \\
& \\
\hline Group training & S45 & Sit down \\
\hline & Stand up \\
\hline &
\end{tabular}

The seven movements (G4, G12, G14, G15, G18, G36, G42) are declared invalid (p-value > 0.05) so they are not listed in Table 2., while the other 40 movements are considered valid because their significance values are obtained through $\mathrm{p}$ - value (Sig. 2-tailed) $<0.05$.

\subsection{Reliability Test}

This test is intended to find out about the consistency in giving questions that causes instructors to have an ease to answer and have a flow of questions that are easy to understand. The decision making in the reliability test is that 1) if the Cronbach's Alpha value $>0.60$ then the questionnaire is presented as reliable or consistent, and 2) if the Cronbach's Alpha value $<0.60$ then the questionnaire is presented as unreliable or inconsistent. It can be seen in Table III, the reliability test values obtained are as follows: 
Table 3. Reliability Test

Cronbach's Alpha 0.743

With the Cronbach's Alpha value at $0.73>0.60$, it can be concluded that the various types of movements that exist are considered to be reliable or consistent.

\subsection{Discussion}

Physical activity has an important role in preventing the decline in the body's ability at a young age, maintaining bodily functions, reducing risk factors for disability, helping in checking chronic pain such as heart disease, diabetes, arthritis, or some types of cancer and the development of quality of life [13]. However, due to the great risk of falling in the elderly [16], it takes a lot of exercise movements that are suitable for the elderly in order to be able to support all daily activities of movement.

The results of interviews conducted with the elderly stated that the usual forms of physical exercise include cycling, aerobics and running. The habit of physical activity is carried out routinely three times a week. However, they have limited space to do activities and rarely use additional tools when doing physical activities. Sometimes the elderly experience increased training load, but they feel muscle aches, stiffness, joint pain, pain when bending, stiffness, panting, etc. Therefore, the elderly want practice with slow movements, more fun, more elderly are involved in order to be able to communicate and make the mind become fresher.

So far the elderly assume there is no physical training model that involves sociological and psychological aspects. Constraints faced by the elderly include jumping, bending, lifting weights and coordinating movements of the feet and hands simultaneously.

Then, testing the validity and reliability of the exercise movement screening questionnaire for the elderly is carried out to ensure that when giving activities there is no malpractice that can be dangerous, such as falls, injuries, and freedom of movement. Easy to fall is closely related to body imbalance, the greater the weight of a person the worse the ability to balance the body [7]. From the research results on the validity and reliability of movement screening, 40 movements are obtained as follows;

The number of movements available in Table 2 shows that according to personal trainers or instructors for the elderly, the movement is safe to do, suitable for the elderly. It is starting with a variety of stretching, pulling, balance, muscle strength, etc. The results of interviews with elderly instructors stated that $57.14 \%$ of elderly instructors did training with a minimum time of 30 minutes. As many as 5 out of 7 instructors said that the exercises carried out were in accordance with the principle of fitness with lowmoderate intensity. Components of fitness in training the elderly include aerobic ability, balance, endurance, strength, flexibility, and speed/ Of course when making movements must be supervised by the instructor, cannot do it alone, because of the high risk of falling [16].

For example, the ability to balance will decrease when weight gain [6], a study in Japan explained that in healthy elderly, a negative relationship with fat condition and waist circumference would be obtained [10]. In other words, more fat deposits and waist width will be positively correlated to the risk of falling in the elderly, but in 
healthy elderly with normal conditions of fat and waist circumference, this will minimize the risk of falls.

With the variations in movement choices in Table 3, there is freedom in moving for the elderly in physical activity. But it cannot be denied, 5 out of 7 instructors said that the elderly were having difficulty in doing the movements. The emergence of the difficulty of the elderly in doing the movements resulted in the instructor choosing a way to do a lot of repetition, helping in completing the movements and making the movements simpler, followed by adding weights from one session to the next. When interviewed the elderly also mentioned that as people who are given training, they prefer to do exercises with movements that are easy to do and in the form of games.

In accordance with various previous research that explain physical activity will provide health benefits for the elderly, maintain bodily functions independently [5], improve their quality of life [3], improve posture stabilization and walking patterns in the elderly in reducing the incidence of falls that often occur [12]. Aside from the physical aspects, the elderly also need support from the socio-psychological aspects [11]. With social support from the surroundings, the elderly will have low blood pressure [1], reduce mortality [9], and improve cognitive function [8]. Many instructors argue that there is no physical exercise that combines the socio-psychological aspects with physical activity. The physical training models recommended by the instructors include low-moderate physical activity which is carried out routinely 3 times a week, movements that are easy, simple and pleasant, prioritizing balance and strength.

\section{Conclusion}

The questionnaire was valid and reliable. Questionnaire regarding screening of exercise movements that are suitable for the elderly have proven to be consistent in the delivery of questions for special instructors in the elderly and are said to be valid for 40 movements, while 7 other movements (Press the arms in front of the chest, Hyperextention, Knees to the left and right chest, Russian twist, turn the arms clockwise, Cow Cat Attitude, and Raise sumo raise calf on the wall) is invalid or not suitable for the elderly to do physical activity.

\section{References}

[1] Birditt, K. S., Newton, N. J., Cranford, J. A., \& Ryan, L. H. (2016). Stress and negative relationship quality among older couples: Implications for blood pressure. Journals of Gerontology - Series B Psychological Sciences and Social Sciences. https://doi.org/10.1093/geronb/gbv023

[2] Birren, J. E., Warner, K. S., Abeles, R. P., Gatz, M., \& Salthouse, T. A. (2006). Handbook of the Psychology of Aging. In Handbook of the Psychology of Aging. https://doi.org/10.1016/B978-0-12-101264-9.X5000-9

[3] Cress, M. E., Buchner, D. M., Prohaska, T., Rimmer, J., Brown, M., Macera, C., ... Chodzko-Zajko, W. (2004). Physical activity programs and behavior counseling in older adult populations. Medicine and Science in Sports and Exercise. https://doi.org/10.1249/01.MSS.0000145451.08166.97

[4] Donald Ary, Lucy Cheser Jacobs, Asghar Razavieh, C. K. S. (2009). Introduction to Research in Education Eighth Edition. In آب و خاك. 
[5] Evans, W. J., \& Grimby, G. (1995). Muscle Performance and Structure in the Elderly as Studied Cross-sectionally and Longitudinally. The Journals of Gerontology Series A: Biological Sciences and Medical Sciences. https://doi.org/10.1093/gerona/50a.special_issue.17

[6] Fox, K. R. (1999). The influence of physical activity on mental well-being. Public Health Nutrition. https://doi.org/10.1017/S1368980099000567

[7] Gao, X., Wang, L., Shen, F., Ma, Y., Fan, Y., \& Niu, H. (2019). Dynamic walking stability of elderly people with various BMIs. Gait and Posture. https://doi.org/10.1016/j.gaitpost.2018.11.027

[8] Gow, A. J., Corley, J., Starr, J. M., \& Deary, I. J. (2013). Which social network or support factors are associated with cognitive abilities in old age? Gerontology. https://doi.org/10.1159/000351265

[9] Holt-Lunstad, J., Smith, T. B., \& Layton, J. B. (2010). Social relationships and mortality risk: A meta-analytic review. PLoS Medicine. https://doi.org/10.1371/journal.pmed.1000316

[10] Ito, T., Kawakami, R., Tanisawa, K., Miyawaki, R., Ishii, K., Torii, S., ... Higuchi, M. (2019). Dietary patterns and abdominal obesity in middle-aged and elderly Japanese adults: Waseda Alumni's Sports, Exercise, Daily Activity, Sedentariness and Health Study (WASEDA'S Health Study). Nutrition. https://doi.org/10.1016/j.nut.2018.05.029

[11] Kaufman, P., \& Wolff, E. A. (2010). Playing and protesting: Sport as a vehicle for social change. Journal of Sport and Social Issues. https://doi.org/10.1177/0193723509360218

[12] Messier, S. P., Thompson, C. D., \& Ettinger, W. H. (1997). Effects of long-term aerobic or weight training regimens on gait in an older, osteoarthritic population. Journal of Applied Biomechanics. https://doi.org/10.1123/jab.13.2.205

[13] Moisescu, P. C. (2014). The Social Integration of Elders Through Free-time Activities. Procedia - Social and Behavioral Sciences. https://doi.org/10.1016/j.sbspro.2014.01.909

[14] Porcari, J. P., Bryant, C. X., \& Comana, F. (2015). Exercise Physiology (Foundations of Exercise Science) 1st Edition.

[15] WHO. (2016). WHO | Proposed working definition of an older person in Africa for the MDS Project. World Health Organization.

[16] Yamada, T., \& Demura, S. ichi. (2009). Relationships between ground reaction force parameters during a sit-to-stand movement and physical activity and falling risk of the elderly and a comparison of the movement characteristics between the young and the elderly. Archives of Gerontology and Geriatrics. https://doi.org/10.1016/j.archger.2007.10.006 